\title{
Investigating Individual's Engagement in Malleable IT within Adaptive Structuration Theory for Individuals
}

\author{
Hazel A. Trapero ${ }^{1,2+}$ \\ ${ }^{1}$ De La Salle University, Philippines \\ ${ }^{2}$ University of the Philippines Cebu, Philippines
}

\begin{abstract}
Innovations are already part of people's daily lives, especially the new generations of cellular phones (smartphones), which is one of the designed malleable information technology (IT) devices. With this innovation, along with different views on individuals' engagement in malleable IT and work productivity, this study aimed to investigate and explore what factors in the users and technology contribute to an individual's adaptation to "malleable IT" and how their use of this IT impacts their individual task performance within the Adaptive Structuration Theory for Individuals (ASTI) by Schmitz, Teng, and Webb [4] in the Philippine setting, with the use of a survey instrument adapted from Schmitz et al. A quantitative analysis of the survey results revealed that innovativeness, creativeness, accumulative affect, and confidence in using the smartphones are influential in the workplace, not on how long the smartphone is at hand, age, gender nor one's educational attainment. However, this study just focused on what individuals can do with the use of malleable IT to achieve a good performance outcome but not the circumstances on how outcomes boost individual's characteristics and engagement in performing the tasks. Further studies on what can continuously motivate one's innovativeness and improve one's confidence are recommended, thus, completing the structuration theory cycle.
\end{abstract}

Keywords: technology and task adaptation, malleable IT, smartphones, structuration, information and communication.

\section{Introduction}

The innovations predicted years ago, as posted in Forbes website [1], are already coming true and have been part of peoples' daily lives. These innovations include the third and fourth generations of cellular phones (smartphones), which are observed to cover the world with connectivity [2], the existence of a futuristic and flexible screen technology with varied distinguished features and capabilities of a given IT over task domains [3] and software applications with inherent flexibility when enabling and assisting a wide variety of work practices without the need for technical customization [4]. This is one of the designed malleable electronic and IT devices which offer tools to make work activities easier for individuals and connectivity that are uncompromised by bulkiness. Malleable IT, thus, refers to smartphones with various features and settings that can be modified, updated, open for another applications installation, interactive and reprogrammable [5].

With the presence of these technologies, individuals learned to embrace and creatively adapt all of these. In fact, as presented by Luden [6], there are already 2.6 billion smartphone subscriptions globally in 2015 and is projected to increase to 6.1 billion smartphone users by 2020. In the Philippines, Euromonitor International [7], stated that the availability of low-cost smartphones pushed smartphones to record $15 \%$ retail volume growth to reach 16.8 million units in 2016 which leads smartphones to become a key digital device in the Philippines.

\footnotetext{
${ }^{+}$Corresponding author.

E-mail address: hazeltrapero@gmail.com
} 
These are believed to be the reasons why enterprises nowadays adapt the Bring Your Own Device (BYOD) strategy in the workplace. This strategy refers to an adaptation of an IT policy where employees are engaged in their personal mobile devices to perform tasks in the work place [8]. Moreover, as reported by Jeff Jones [9], one of Microsoft's researches found out that $67 \%$ of people are using their personal devices in the workplace today. However, a survey with some employers by Madeline Farber [6] that was published in Fortune.com revealed that using smartphones at work leads to a high cost of low productivity. In fact, $48 \%$ of employers said that smartphone distractions compromised the quality of work.

With all these innovations, along with different views on individuals' engagement in malleable IT and work productivity, it is the interest of this study to investigate and explore what factors in the users and technology contribute to an individual's adaptation to "malleable IT" and how their use of this IT impacts their individual task performance.

\section{Conceptual Framework}

Adaptive Structuration Theory (AST), the forerunner of ASTI, was inspired by Anthony Gidden's concept of structuration [11],[12]. It pertains to the concepts of structuration to group decision support systems (GDSS), which organized the IT-facilitated social interactions as Input $\rightarrow$ Process $\rightarrow$ Output sequences. This theory looked into mutual influence of technology and social practices.

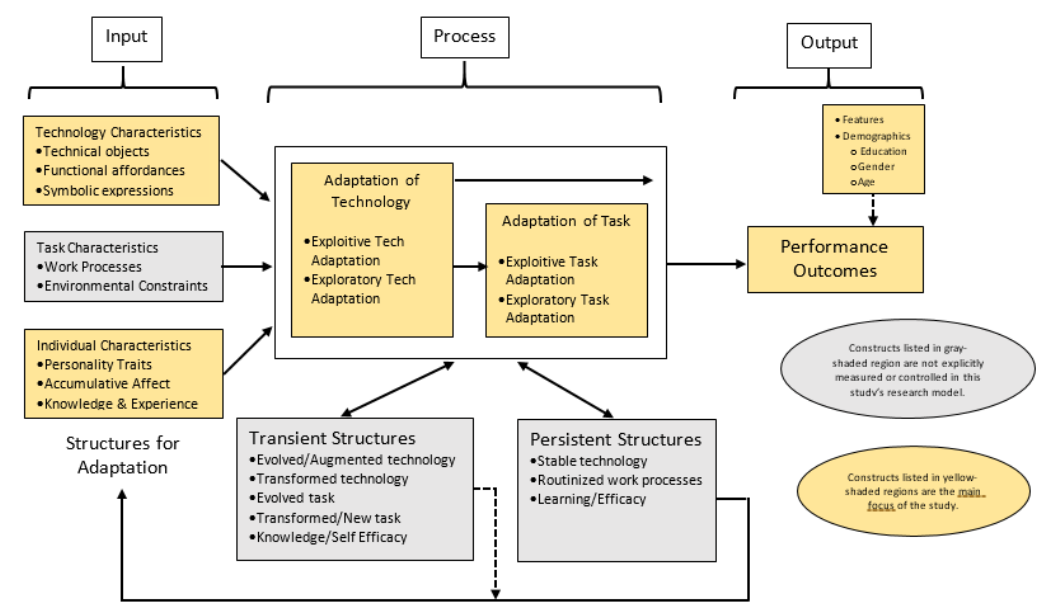

Fig. 1: Adaptive structuration theory for individuals.

ASTI is an extension of the AST framework to the level of individuals so as to explain adaptation of malleable IT, specially by nontechnical users. This framework, as shown in Figure 1, was developed and proposed by Schmitz, Teng, and Webb [4] mainly because they saw the importance of capturing the complexity of malleable IT use by individuals, not just by groups and teams, including those who are nontechnical users. This framework is also intended to present a more detailed description of user behaviors. As it is shown in Figure 1, all the adaptation elements (research variables) are classified and divided into Adaptation of Technology and Adaptation of Task as a result of Schmitz et al. study.

Nevertheless, it was observed that the role of technology influenced the cognitive and behavioral participation of individuals to the point that their interpretations of technology could lead to actions patterns that completely shaped the strategic and structural orientation of the organization. This organizational change relies on workers who are driven by some agents, events, and things to accomplish tasks. So, there is a need to evaluate the individual's driving factors to work and do the organizational activities and how they are going to accomplish it [13].

\section{Methodology}

Fifty (50) working respondents were identified based on convenience sampling. Some of them were a group of individuals who took up graduate studies at De La Salle University (DLSU) and some acquaintances on Facebook who are already working, who were later found to be a mix of employed and 
freelance workers. However, five (5) were removed from the list since they confirmed that they did not use the mobile phones at work, which is the controlled variable in the study. Among the forty-five (45) respondents, $58 \%$ were females and $42 \%$ were males, $49 \%$ belong to age bracket of 21-30 years old (YO), $33 \%$ were within $31-40$ YO bracket, $16 \%$ were within $41-50$ YO, while $2 \%$ belong to 51-60 YO.

A 7-scale survey instrument by Schmitz et al. [4] was answered by the respondents with eight (8) main sections (research variables) as listed in Table 1. A few demographic data such as education, gender, and age and other controls like the number of features available in their mobile phone were also collected from them to strengthen the investigation on task performance, which were based on ASTI.

Table 1: List of sections in the survey instrument

\begin{tabular}{|c|c|}
\hline SECTIONS & DESCRIPTION \\
\hline Performance & $\begin{array}{l}\text { Employee's task performance, which are actions that are typically included in the job } \\
\text { descriptions }\end{array}$ \\
\hline Exploitive Technology & Users customize technology features in the mobile phone in relation to one's perception \\
\hline Adaptation & on technological standard and taking advantage of technology. \\
\hline Exploratory Technology & Users formulate new technology features or install applications in the mobile phone \\
\hline Adaptation & that are unusual to others and far from standard usage. \\
\hline Exploitive Task Adaptation & $\begin{array}{l}\text { Users try to reinvent existing task processes with the use of mobile phones but make } \\
\text { sure to maintain the current structure and objective of those processes. }\end{array}$ \\
\hline Exploratory Task & Users try to reinvent existing task processes with the use of mobile phones at the same \\
\hline Adaptation & time, generate new target objectives of those processes. \\
\hline Personality Trait & $\begin{array}{l}\text { Individual's disposition to experiment and try out something new in information } \\
\text { technology and with positive vision of using this as a tool to be progressive in doing the } \\
\text { assigned task in the workplace. }\end{array}$ \\
\hline Accumulative Affect & $\begin{array}{l}\text { Individual's attitude and understanding on his/her ability to use technology, which } \\
\text { includes one's capability in utilizing all the features in the mobile phone. }\end{array}$ \\
\hline $\begin{array}{l}\text { Knowledge and Experience } \\
\text { with IT }\end{array}$ & $\begin{array}{l}\text { Length of time the user is engaged in the mobile phone and use it in any way one can, } \\
\text { especially in the workplace. }\end{array}$ \\
\hline
\end{tabular}

All the data were carefully analyzed through different statistical treatments with the assistance of a professional statistician. Results and findings were formulated, and recommendations were presented for the betterment of the study.

\section{Results}

Table 2: Correlations of variables

\begin{tabular}{|c|c|c|c|c|}
\hline \multirow[t]{2}{*}{ Variables } & \multicolumn{2}{|c|}{$\begin{array}{l}\text { Test Statistics } \\
(\alpha=0.05)\end{array}$} & \multirow[t]{2}{*}{$\begin{array}{c}\text { Correlation } \\
\text { Coefficient }(\rho) \\
\end{array}$} & \multirow[t]{2}{*}{$\begin{array}{c}\text { Strength of } \\
\text { Relationship }\end{array}$} \\
\hline & $t_{c}$ & $t_{t a b}$ & & \\
\hline $\mathrm{PT} \rightarrow \mathrm{E}-\mathrm{TECH}$ & $5.109 *$ & 2.021 & 0.615 & Strong \\
\hline $\mathrm{PT} \rightarrow \mathrm{R}-\mathrm{TECH}$ & $6.228 *$ & 2.021 & 0.689 & Strong \\
\hline $\mathrm{AA} \rightarrow \mathrm{E}-\mathrm{TECH}$ & $3.352 *$ & 2.021 & 0.455 & Moderate \\
\hline $\mathrm{AA} \rightarrow \mathrm{R}-\mathrm{TECH}$ & $2.166^{*}$ & 2.021 & 0.314 & Weak \\
\hline $\mathrm{KE} \rightarrow \mathrm{E}-\mathrm{TECH}$ & $0.322^{\mathrm{ns}}$ & 2.021 & 0.0495 & Very Weak \\
\hline $\mathrm{KE} \rightarrow \mathrm{R}-\mathrm{TECH}$ & $0.184^{\mathrm{ns}}$ & 2.021 & 0.028 & Very Weak \\
\hline E-TECH $\rightarrow$ E-TASK & $5.073^{*}$ & 2.021 & 0.612 & Strong \\
\hline E-TECH $\rightarrow$ R-TASK & $5.600 *$ & 2.021 & 0.649 & Strong \\
\hline R-TECH $\rightarrow$ E-TASK & $5.084 *$ & 2.021 & 0.613 & Strong \\
\hline R-TECH $\rightarrow$ R-TASK & $4.864 *$ & 2.021 & 0.600 & Strong \\
\hline E-TECH $\rightarrow$ PERF & $2.696 *$ & 2.021 & 0.380 & Weak \\
\hline R-TECH $\rightarrow$ PERF & $1.119^{\mathrm{ns}}$ & 2.021 & 0.168 & Very Weak \\
\hline E-TASK $\rightarrow$ PERF & $3.154 *$ & 2.021 & 0.433 & Moderate \\
\hline R-TASK $\rightarrow$ PERF & $3.738 *$ & 2.021 & 0.495 & Moderate \\
\hline FEAT $\rightarrow$ PERF & $(-) 0.158^{\mathrm{ns}}$ & 2.021 & -0.024 & Very weak \\
\hline
\end{tabular}


Table 2 shows that the there is a significant rank correlation between PT and adaptation as well as between AA and adaptation. However, there is no significant rank correlation between respondents' KE and adaptation. The table also shows a strong rank correlation between technology adaptation and task adaptation. In addition, PERF is associated with E-TECH, E-TASK, and R-TASK but not with R-TECH. PERF is also not associated with smartphone features.

Table 3: Mediation Test results

\begin{tabular}{ccccc}
\hline \multirow{2}{*}{ Variables } & \multicolumn{2}{c}{ Test Statistics } & Sobel Test & $P$-value \\
\cline { 2 - 5 } & $t_{a}$ & $t_{b}$ & & \\
E-TECH $\rightarrow$ E-TASK $\rightarrow$ PERF & $5.073 *$ & 3.154 & 2.678 & $0.001^{*}$ \\
E-TECH $\rightarrow$ R-TASK $\rightarrow$ PERF & $5.600^{*}$ & 3.738 & 3.109 & $0.002^{*}$ \\
R-TECH $\rightarrow$ E-TASK $\rightarrow$ PERF & $5.084^{*}$ & 3.154 & 2.680 & $0.007 *$ \\
R-TECH $\rightarrow$ R-TASK $\rightarrow$ PERF & $4.864 *$ & 3.738 & 2.964 & $0.003^{*}$ \\
\hline \multicolumn{7}{c}{ *Significant }
\end{tabular}

Table 3 presents the mediation test results using Sobel second order product of coefficients test, also known as delta method, but based on the computed $t$ values. All mediation results are significant. Thus, the correlation between technology adaptations and PERF, as well as the between task adaptations and PERF, are mediated by both the E-TASK and R-TASK.

Table 4: Demographics and other controls and performance

\begin{tabular}{lccl}
\hline \multirow{2}{*}{ Variables } & \multicolumn{2}{c}{ Test Statistics } & \multirow{2}{*}{ Remarks } \\
\cline { 2 - 3 } & \multicolumn{2}{c}{$(\alpha=0.05)$} & \\
\cline { 2 - 4 }${ }^{2}$ & $X^{2}{ }_{t a b}$ & \\
AGE $\rightarrow$ PERF & $7.873^{\text {ns }}$ & 16.919 & Not significant \\
EDUER $\rightarrow$ PERF & $5.359^{\text {ns }}$ & 7.815 & Not significant \\
\hline & $5.830^{\text {ns }}$ & 12.592 & Not significant \\
\hline
\end{tabular}

Table 4 shows that age, gender, and educational attainment are not related to worker's performance on tasks assigned to him/her.

\section{Discussions}

The results show that the respondents' willingness to experiment with mobile phones led them to eagerly try hard to do work tasks using their mobile phones and utilize the various features that can be found in it. This result confirms Idemudia and Raisinghani's [10] claim that mobile phones are increasingly valuable and has the capability of helping people to be more effective and efficient.

In addition, respondents' eagerness to do experimentation with their mobile phones is moderately affected by their confidence of their ability to use the mobile phones for different activities like e-mails, and other applications. The drive to experiment one's mobile phone is probably pushing them to find out new work-related tasks and how these new tasks are being performed with the use of a mobile phone which enables them to perform the task better.

The length of time the mobile phone was acquired cannot affect their desire to experiment with it. Their innovativeness and boldness to try all things may be the primary reasons why they exploit everything about the mobile phone, not on how long the person is using it. Similarly, the number of features in the user's mobile phone does not guarantee a good performance when doing the tasks assigned to them. Age, gender, and educational attainment do not also affect individual's performance. This strengthens the Technology Acceptance Model (TAM) which emphasized that the use of an information system is determined by the behavioural intention, however, that behavioural intention is figured out by one's attitude towards its usage [14].

\section{Conclusion}


Innovativeness and creativity are highly influential and very much needed in the workplace, especially in the success of work tasks. Accumulative affect and confidence are also other predictors of having a good performance, but it depends on whether an individual has the desire to really find the right strategies, like the use of smartphones. It does not necessarily depend on how long the mobile phone was at hand, on one's age, gender nor the educational attainment of a person.

Indeed, the Adaptive Structuration Theory for Individuals (ASTI) really helps in identifying factors in users and technology that contribute to an individual's adaptation to "malleable IT" and how engagement of this IT impacts their individual task performance.

However, this study just mainly focused on what individuals can do with the use of malleable IT to achieve a good performance outcome but not including the circumstances on how performance outcomes can, in turn, boost and uplift an individual's characteristics and enable one to be more engaged in performing specific task at a specific objective. It is also recommended to conduct further studies on what can continuously motivate the individual's innovativeness and if performance results can make one's experience to be a happy one and may lead to better working condition with the use of malleable IT, thus, completing the structuration theory cycle. Further research on the different types of workers is also recommended.

\section{Acknowledgements}

This research is partially supported by Dr. Raymund Sison. I thank him for his insights, questions, comments and expertise that greatly assisted the research.

I also thank Dr. Cherry Malaque for sharing her wisdom and time in proofreading the manuscript.

\section{References}

[1]. Kain, E. The Future of Touchscreen Technology. 2012. Accessed on November 9, 2016 from www.forbes.com/sites/erikkain /2012/02/19/the-future-of-touchscreen-technology/\#775fc90f10a1.

[2]. Klashner, R. and Sabet, S. Designing Malleable Cyberinfrastructure to Breach the Golden Barrier. Journal of Information Technology Theory and Applications. 2004, 6(3): 59-84.

[3]. Moore, J.B. and Stafford, T.F. Impact of Work System Reconceptualization and Motivation on Information Technology Infusion. Information Technology and Organizations: Trends, Issues, Challenges and Solutions. Idea Group Publishing, USA, 2003, Volume 1.

[4]. Schmitz, K. W., Teng, J. T. C., \& Webb, K. J. Capturing the Complexity of Malleable IT Use: Adaptive Structuration Theory for Individuals. Availability: In Stock. MIS Quarterly. 2016, 40(3): 663-686.

[5]. Kallinikos, J. Aaltonen, A., and Marton, A. The Ambivalent Ontology of Digital Artifacts. MIS Quarterly. 2013, (37:2): 357-370.

[6]. Luden, I. 6.1b Smartphone Users Globally by 2020, Overtaking Basic Fixed Phone Subscriptions, 2015. Accessed on November 9, 2016. https://techcrunch.com/2015/06/02/6-1b-smartphone-users-globally-by-2020-overtakingbasic-fixed-phone-subscriptions/.

[7]. Euromonitor International. Mobile Phones in the Philippines. 2016. Accessed on November 11, 2016 from http://www.euromonitor.com/mobile-phones-in-the-philippines/report

[8]. IBM. BYOD: Bring Your Own Device. 2017. Accessed on September 1, 2017 from https://www.ibm.com/mobile/bring-your-own-device/

[9]. Jones, J. BYOD - is it Good, Bad or Ugly from the User Viewpoint? 2013. Accessed on September 1, 2017 from https://blogs.microsoft. com/microsoftsecure/2012/07/26/byod-is-it-good-bad-or-ugly-from-the-user-viewpoint/

[10]. Idemudia, E.C. and Raisinghani, M.S. The Influence of Cognitive Trust and Familiarity on Adoption and Continued Use of Smartphones: An Empirical Analysis. Journal of International Technology and Information Management. 2014, (23:2): 69-IV.

[11]. Desanctis, G. And Poole, M.S. Capturing the Complexity in Advance Technology Use: Adaptive Structuration Theory. Organization Science. 1994, 5(2): 121-147.

[12]. Joas, H. Giddens' Theory of Structuration: Introductory Remarks on a Sociological Transformation of the 
Philosophy of Praxis. International Sociology. 1987, 2(1): 13-26.

[13]. Yeo, R. K., \& Marquardt, M. J. Think Before You Act: Organizing Structures of Action in Technology-Induced Change. Journal of Organizational Change Management. 2015, 28(4): 511-528.

[14]. Davis, F.; Bagozzi, R.; and Warshaw, R. User Acceptance of Computer Technology: A Comparison of Two Theoretical Models. Management Science. 1989, vol 35: 982-1003. 